\title{
Peroxidative Hemolysis of Red Blood Cells from Patients with Abetalipoproteinemia (Acanthocytosis) *
}

\author{
James T. Dodge, $\dagger$ Gerald Cohen, Herbert J. Kayden, $\$$ and \\ Gerald B. Phillips $\S$ \\ (From the Departments of Medicine, Biochemistry, and Psychiatry, College of Physicians and \\ Surgeons, Columbia University, The New York State Psychiatric Institute, and the \\ Department of Medicine, New York University School of Medicine, \\ New York, N. Y.)
}

Summary. The effect of peroxidative stress on tissue was studied by exposure of red blood cells (RBC) from patients with abetalipoproteinemia to minute amounts of $\mathrm{H}_{2} \mathrm{O}_{2}$ in vitro. Red blood cells from untreated patients showed a marked sensitivity to $\mathrm{H}_{2} \mathrm{O}_{2}$, as evidenced by hemolysis and lipid peroxidation (peroxidative hemolysis).

The appearance of lipid peroxidation products in sensitive cells after exposure to $\mathrm{H}_{2} \mathrm{O}_{2}$ was indicated by 1) increases in the 2-thiobarbituric acid (TBA) reaction of trichloroacetic acid extracts, 2) increases in ultraviolet light absorbency of lipid extracts, and 3) decreases in polyunsaturated fatty acids. These changes were accompanied by a decrease in phosphatidyl ethanolamine and phosphatidyl serine in the RBC lipid extract. Similar lipid changes on exposure to $\mathrm{H}_{2} \mathrm{O}_{2}$ were observed in the $\mathrm{RBC}$ from vitamin E-deficient rats.

Treatment of the patients with $d$ - $\alpha$-tocopherol polyethylene glycol succinate by mouth, or addition of $d l-\alpha$-tocopherol to the incubation medium protected the $\mathrm{RBC}$ from peroxidative hemolysis. Tocopherol appears to provide a primary biologic defense against peroxidative hemolysis.

The presence of nitrite or carbon monoxide, which produced methemoglobin and carboxyhemoglobin, respectively, inhibited peroxidative changes, suggesting a catalytic role for oxy- or deoxyhemoglobin.

Substances that prevented lipid peroxidation also prevented hemolysis; in addition, lipid peroxidation appeared to precede hemolysis. These observations suggested that hemolysis was a consequence of lipid peroxidation.

\section{Introduction}

Lipids extracted from human red blood cells are highly susceptible to autoxidation (2). The possibility of a comparable lipid alteration occur-

* Submitted for publication July 1, 1966; accepted November 10, 1966.

This investigation was supported by U. S. Public Health Service grants HE-02907, HE-01045, and HE-06481.

A preliminary report was published in abstract form (1).

$\dagger$ This work was done during the tenure of an Advanced Research Fellowship of the American Heart Association. ring in the intact cell has been suggested by the appearance of substances reactive with 2-thiobarbituric acid when $\mathrm{RBC}$ from vitamin $\mathrm{E}$-deficient animals were exposed in vitro to hydrogen peroxide (3-6) or dialuric acid $(3,7)$, or in vivo to hyperbaric oxygen (8). Indeed, lipid peroxidation has been implicated as a mechanism for some of the manifestations of vitamin $\mathrm{E}$ deficiency in

$\ddagger$ Recipient of U. S. Public Health Service Career Research Development Award K3 HE-14-828.

$\S$ Recipient of Lederle Medical Faculty Award. Address requests for reprints to Dr. Gerald B. Phillips, Roosevelt Hospital, 428 W. 59th St., New York, N. Y. 10019. 
experimental animals $(3,4,7,9,10)$ and man (5, 11, 12). Recently, Kayden and Silber reported that patients with abetalipoproteinemia (acanthocytosis) were deficient in vitamin $\mathrm{E}$; in fact, the serum tocopherol levels were the lowest reported for man (13). These patients presented a unique opportunity to investigate lipid oxidation in intact human RBC. Rats with experimental vitamin E deficiency were also studied. Red blood cells were exposed to minute amounts of $\mathrm{H}_{2} \mathrm{O}_{2}$ as a stressing agent; hemolysis and lipid peroxidation (peroxidative hemolysis) resulted. This report is the first description of alterations in the RBC phospholipid fatty acids that characterize peroxidative hemolysis of RBC from patients or experimental animals with vitamin $\mathrm{E}$ deficiency. Moreover, evidence suggests that these lipid alterations portend hemolysis.

\section{Methods}

Each of the four following patients with abetalipoproteinemia has been included in previous investigations: A.V. (13), a girl born in 1957; and R.B. (13-17), M.S. (13, 16-18), and R.I. (15, 19-21), boys born in 1956, 1954, and 1953, respectively. Control subjects were healthy males and females between the ages of 20 and 40 who were taking no medication. Vitamin E deficiency was produced in male and female Wistar rats by feeding a "tocopherol-deficient diet" ${ }^{1}$ from weaning until the age of 6 months, when this study was performed.

We determined plasma tocopherol levels by a micromethod using the Emmerie-Engle reaction (22). The autohemolysis test was performed by sterile incubation of defibrinated blood at $37^{\circ} \mathrm{C}$ for 48 hours essentially as described by Young, Izzo, Altman, and Swisher (13, 23); samples were run in duplicate and average values reported.

Exposure of $\mathrm{RBC}$ suspensions to $\mathrm{H}_{2} \mathrm{O}_{2}$ vapor. Heparinized $^{2}$ venous blood was stored between 0 and $4^{\circ} \mathrm{C}$ for up to 18 hours before the RBC were isolated by centrifugation, washed three times in an equal volume of isotonic saline at room temperature, and studied. A 10\% suspension of the washed RBC in isotonic saline-phosphate buffer, $\mathrm{pH} 7.4$ (24), was prepared; 4.5-ml samples were placed in 25- $\mathrm{ml}$ Warburg flasks and exposed to minute amounts of $\mathrm{H}_{2} \mathrm{O}_{2}$ by the method of Cohen and Hochstein $(25,26)$. The $0.3 \mathrm{ml}$ of $30 \% \quad \mathrm{H}_{2} \mathrm{O}_{2}$ that was

\footnotetext{
${ }^{1}$ Nutritional Biochemicals Corp., Cleveland, Ohio.

2 Heparin sodium, 1,000 IU USP per ml, containing benzyl alcohol, $9 \mathrm{mg}$ per $\mathrm{ml}$, from the Upjohn Co., Kalamazoo, Mich., was used in preliminary experiments. The benzyl alcohol interfered, however, with ultraviolet light absorbency measurements. Therefore, when spectrophotometry was performed, another preparation was used: crystalline heparin sodium, 120 IU USP per mg, Connaught Medical Research Labs., Toronto, Canada.
}

placed in the center well diffused into the RBC suspension at a rate of approximately $2.3 \mu$ moles per hour 3 while the flasks were shaken in a Dubnoff metabolic incubator 90 to 100 times a minute at $37^{\circ} \mathrm{C}$. In order to facilitate lipid extraction in later experiments in which phospholipid and fatty acid analyses were performed, we increased the hematocrit of the RBC suspension to between 30 and $40 \% .4$

Analysis of the incubation suspension. The per cent hemolysis was calculated from the hemoglobin concentration, which was determined by a cyanomethemoglobin method (26) on the supernatant of the incubation suspension after centrifugation and appropriate dilution. The value for $100 \%$ hemolysis was obtained by measurement of hemoglobin concentration in a sample of the $\mathrm{RBC}$ suspension lysed in the saline-phosphate buffer diluted to be equivalent to $0.1 \%$ saline.

The TBA test was performed on a trichloroacetic acid extract of a sample of the incubation suspension with absorbency measurement at $532 \mathrm{~m} \mu$ (7). This test provides an index of lipid peroxidation by determination of the malonylaldehyde released on acid hydrolysis $(27,28)$.

Analysis of RBC lipid. Lipids were extracted at room temperature from $3.0 \mathrm{ml}$ of the $10 \%$ suspension of RBC. After centrifugation at $3,000 \times g$ and aspiration of the supernatant, about $0.3 \mathrm{ml}$ of packed RBC (or ghosts) remained, and this amount was taken as 1 vol for calculation of the quantity of reagents used. One vol of methanol that contained the antioxidant 2,6-di-tert-butyl 4 methyl phenol (BHT), , $65 \mathrm{mg}$ per $100 \mathrm{ml}$, and 9 vol of methanol alone were added, mixed, and allowed to stand for 30 minutes. Ten vol of chloroform 7 was added, mixed, and allowed to stand for an additional 30 minutes.

\footnotetext{
3 Approximately $5.5 \times 10^{-10} \mu$ mole of $\mathrm{H}_{2} \mathrm{O}_{2} / \mathrm{RBC}$ per hour.

4 Approximately $2 \times 10^{-10} \mu$ mole of $\mathrm{H}_{2} \mathrm{O}_{2} / \mathrm{RBC}$ per hour.

5 "Ionol, CP," a gift from the Shell Chemical Co., New York, N. Y.

6 Approximately one part BHT per 100 parts of total lipid, by weight. This amount of BHT was approximately 10 times more than was necessary to prevent autoxidation of dried lipid extracts of normal human RBC (2). As a result of our first experiments with RBC from patients with abetalipoproteinemia in which an antioxidant was not employed, we found it necessary to add $\mathrm{BHT}$ in order to prevent the artifactual development of large amounts of lipid peroxides in the extract. BHT did not appear to reduce lipid peroxides, specifically hydroperoxides, once they developed. This conclusion was based on studies of cod liver oil during various stages of autoxidation, which showed that the peroxide value, determined by an iodometric method, did not decrease when BHT was added after autoxidation had occurred. Because BHT has a characteristic absorbence in the ultraviolet region of the spectrum (29), absorbency data were corrected for its presence.

7 Chloroform was purified by distillation in an all glass system and stabilized with methanol 1:50 (vol/vol).
} 
After centrifugation at $3,000 \times g$ for 5 minutes, the supernatant was collected and 10 vol of chloroform followed by 6 of $0.05 \mathrm{M} \mathrm{KCl}$ was added, mixed, and allowed to stand overnight at $-25^{\circ} \mathrm{C}$. When warmed to room temperature, the phases separated cleanly. The lower phase was collected and evaporated in vacuo at $40^{\circ} \mathrm{C}$. Complete exclusion of the upper phase was essential for reproducible ultraviolet light absorbency measurements. The lipid extract was dissolved in 5 vol of chloroform and analyzed the same day. In experiments where the hematocrit of the incubation suspension was between 30 and $40 \%$, lipids were extracted without prior centrifugation from a $2.0-\mathrm{ml}$ sample that was taken as 1 vol for calculation of the quantity of reagents.

The absorbency at 234 and $268 \mathrm{~m} \mu$ of the lipid extract dissolved in methanol provides a convenient index of peroxidation of the RBC lipids (2), as conjugated dienes and conjugated trienes that absorb at these wavelengths, respectively, are intermediates during autoxidation and peroxidation of polyunsaturated fatty acids (30). The extinctions were expressed in terms of the molar concentration of lipid phosphorus. To determine lipid phosphorus, an adaptation of Marinetti's modification of Bartlett's method was used (31).

We determined the RBC phospholipid distribution by thin-layer chromatography (TLC) on silica gel $H R, 8$ $0.5 \mathrm{~mm}$ thick, with the developing solvent chloroformmethanol-glacial acetic acid-water $25: 15: 4: 2$ (vol/vol)

(32) to which we added BHT at a concentration of 50 $\mathrm{mg}$ per $100 \mathrm{ml}$ to prevent autoxidation during chromatography (33). The spots were made visible in ultraviolet light by spraying with a dichlorofluorescein solution, and the phosphorus content of each spot was analyzed (31).

To prepare $\mathrm{RBC}$ total phospholipid fatty acid methyl esters, we employed TLC of the lipid extract on silica gel HR, $0.5 \mathrm{~mm}$ thick, in hexane-diethyl ether-glacial acetic acid 70:30:1 (vol/vol) containing BHT at a concentration of $50 \mathrm{mg}$ per $100 \mathrm{ml}$. The phospholipid, which remained at the origin, was scraped into an ampul, and boron trifluoride-methanol reagent ${ }^{9}$ was added; the ampul was flushed with nitrogen, sealed, and heated in boiling water for 90 minutes according to the method of Morrison and Smith (34). Four $\mathrm{ml}$ of pentane $\mathbf{1 0}$ and $1.0 \mathrm{ml}$ of water were added and mixed, and the fatty acid methyl esters were recovered in the pentane phase. Long chain hydroxy fatty acid methyl esters, if present, were not recovered quantitatively by the single extraction with pentane (34).

Methyl esters of RBC total lipid fatty acids were prepared without prior lipid extraction as follows: A 1.0$\mathrm{ml}$ sample of the incubation suspension was hydrolyzed in $5.0 \mathrm{ml}$ of aqueous $2 \mathrm{~N} \mathrm{HCl}$, which contained $25 \mu \mathrm{g}$ of $d l$ - $\alpha$-tocopherol 1,11 and $12 \mu \mathrm{g}$ of $\mathrm{BHT}$, in a sealed tube at $110^{\circ} \mathrm{C}$ for 18 hours. The fatty acids were ex-

8 Brinkmann Instruments, Inc., Westbury, N. Y.

9 Applied Science Laboratories, Inc., State College, $\mathrm{Pa}$.

${ }^{10}$ Distilled in an all glass system over $\mathrm{KMnO}_{4}$ and contained BHT, $5 \mathrm{mg}$ per $100 \mathrm{ml}$.

11 One $\mathrm{mg}=1 \mathrm{IU}$. tracted with diethyl ether that contained BHT, $5 \mathrm{mg}$ per $100 \mathrm{ml}$, and the ether extract was dehydrated over $\mathrm{Na}_{2} \mathrm{SO}_{4}-\mathrm{NaHCO}_{3}, 4: 1$, transferred to an ampul, and evaporated to dryness with a stream of nitrogen. The fatty acids were converted to their methyl ester derivatives by adding $1.0 \mathrm{ml}$ of $\mathrm{BF}_{3}$-methanol reagent and heating the sealed ampul for 30 minutes at $100^{\circ} \mathrm{C}$. The fatty acid methyl esters were extracted from the $\mathrm{BF}_{3}$ methanol with pentane and purified by TLC on silica gel $\mathrm{HR}$ with development in benzene (34) that contained BHT, $50 \mathrm{mg}$ per $100 \mathrm{ml}$.

Gas-liquid chromatography (GLC) was performed with a Barber-Colman instrument, model 5000, equipped with paired 8-foot columns of EGSS-X $8 \%$ on Gaschrom $\mathrm{P}, 100 / 120$ mesh, 9 and dual flame ionization detectors. The nitrogen flow rate was $50 \mathrm{ml}$ per minute at the inlet. The column temperature was maintained at $165^{\circ} \mathrm{C}$ for 10 minutes after injection of the sample, then increased at $2^{\circ} \mathrm{C}$ per minute to $200^{\circ} \mathrm{C}$. Thirty-eight peaks were observed and identified on isothermal runs at $185^{\circ} \mathrm{C}$ by use of a semilogarithmic plot of retention time data and calculation of type I and type II separation factors according to Ackman and Burgher (35). Known fatty acid methyl ester mixtures (NHI-type mixtures $\mathrm{KB}, \mathrm{KD}$, and $\mathrm{KF}$, and mixtures $\mathrm{K} 107$, L203, L205, and L207) ${ }^{9}$ were used as primary reference standards and cod liver oil fatty acid methyl esters as secondary reference standards (36). Identification was confirmed by GLC of the RBC total phospholipid methyl esters on a less polar column, EGSS-Y $12 \%, 9^{9}$ at $190^{\circ} \mathrm{C}$, and by GLC of the methyl ester fractions separated according to their degree of unsaturation by TLC of the acetoxymercuri-methoxy derivatives $(31,37)$.

Peak areas were calculated by means of a Disc chart integrator. Quantitative results with National Heart Institute fatty acid methyl ester standard mixtures $\mathrm{KB}$, $\mathrm{KD}$, and $\mathrm{KF}^{9}$ agreed with the stated composition data with a relative error of less than $2 \%$ for major components ( $>10 \%$ of the mixture) and less than $3.5 \%$ for minor components. BHT eluted with a retention time similar to that of methyl myristate (2). When taken through the $\mathrm{BF}_{3}$-methanol methylation procedure (34), BHT gave rise to an additional peak, which had a retention time similar to that of methyl palmitoleate (2). Therefore, myristic and palmitoleic acids were not quantified. We recalculated the per cent composition data for $\mathrm{RBC}$ samples exposed to $\mathrm{H}_{2} \mathrm{O}_{2}$ by multiplying the value for each fatty acid by the factor that made the per cent of palmitic acid in the exposed sample equal to the per cent in the control sample. Palmitic acid was selected as the reference peak because it is saturated and should be affected relatively less by peroxidation than unsaturated moieties, and because it is a large component and may be accurately quantified. This method of calculation shows the relative changes that occur in the concentration of the individual acids if palmitic acid is assumed to be constant. Should palmitic acid be lost, however, this method for expression of the data would underestimate losses of other fatty acids. The increase in the relative amount of lignoceric acid (24:0) (Tables 
III, IV, V) does indicate a loss in palmitic acid with peroxidation, presumably because some peroxidized phosphatidyl ethanolamine and phosphatidyl serine, which contain palmitic acid but almost no 24:0 (31), were not in the extract.

\section{Results}

RBC from the untreated patients with abetalipoproteinemia showed a marked sensitivity to $\mathrm{H}_{2} \mathrm{O}_{2}$ (Figure 1). Seventy-nine to $95 \%$ of the cells from two untreated patients lysed during 4 to 6 hours of exposure to minute amounts of $\mathrm{H}_{2} \mathrm{O}_{2}$, whereas less than $3 \%$ of the $\mathrm{RBC}$ from normal subjects lysed during 10 hours, and less than $7 \%$ during 21 hours of exposure.

Evidence was found for lipid peroxidation in the $\mathrm{RBC}$ from untreated patients with abetalipoproteinemia after exposure to $\mathrm{H}_{2} \mathrm{O}_{2}$ in vitro (Table I). This evidence consisted of striking increases in the TBA reaction (malonylaldehyde) on the trichloroacetic acid extracts of the cell suspensions and increases in the absorbencies at 234 and $268 \mathrm{~m} \mu$ (conjugated dienes and conjugated trienes, respectively) of the lipid extracts. Since it appears that certain peroxidized lipids may be lost, in part, during the RBC extraction procedure (see below), the ultraviolet absorbency measured may underestimate the degree of peroxidation that has occurred. Addition of $d l-\alpha$-tocopherol, ${ }^{12}$ glucose, or sodium nitrite to the incubation solution prevented hemolysis as well as increase

12 Calbiochem, Los Angeles, Calif.

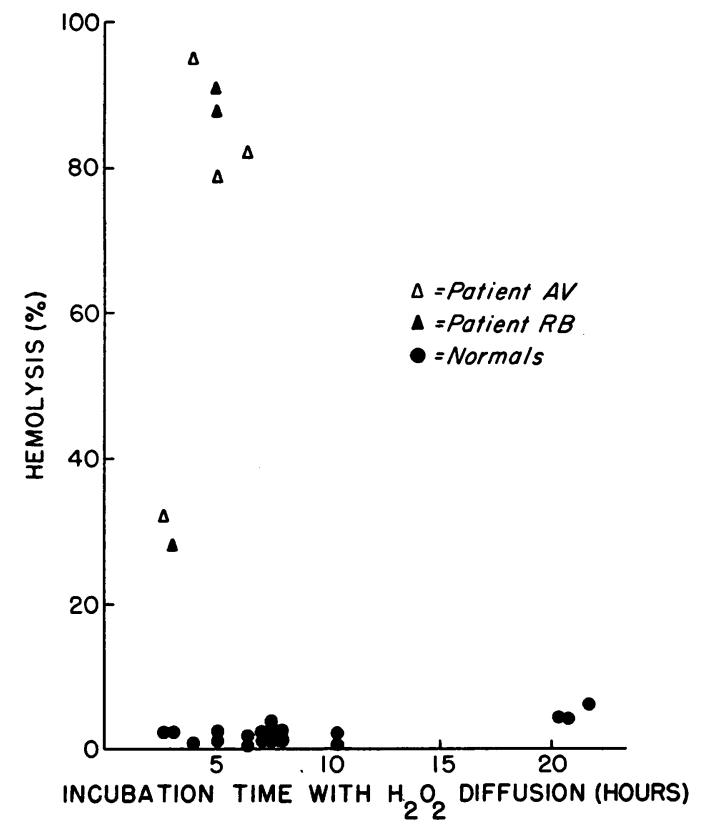

Fig. 1. EFFECt OF EXPOSURE OF RED BLOOD CELlS (RBC) FROM UNTREATED PATIENTS WITH ABETALIPOPROTEINEMIA To $\mathrm{H}_{2} \mathrm{O}_{2}$ IN vitro. Two patients, $A$. V. and $\mathrm{R}$. B., who had not received vitamin $E$, were studied on three separate occasions. The control determinations were performed on samples from 10 normal subjects on seven separate occasions.

in the TBA reaction during the exposure period; partial protection of the cells was provided by carbon monoxide. In a single experiment with the $\mathrm{RBC}$ from patient R.B., the exposure to $\mathrm{H}_{2} \mathrm{O}_{2}$ was continued for 24 hours; at that time, the to-

TABLE I

Effect of $\mathrm{H}_{2} \mathrm{O}_{2}$ in vitro on red bload cells $(\mathrm{RBC})$ from untreated patients with abetalipoproteinemia

\begin{tabular}{|c|c|c|c|c|}
\hline \multirow[b]{3}{*}{ Conditions } & \multicolumn{4}{|c|}{ Analyses after incubation of $\mathrm{RBC}$ with $\mathrm{H}_{2} \mathrm{O}_{2}$ diffusion* } \\
\hline & \multicolumn{2}{|c|}{$\begin{array}{l}\text { Analyses of } \\
\text { suspension }\end{array}$} & \multicolumn{2}{|c|}{$\begin{array}{c}\text { Absorbency of } \\
\text { total lipid† }\end{array}$} \\
\hline & Hemolysis & TBA test & $234 \mathrm{~m} \mu$ & $268 \mathrm{~m} \mu$ \\
\hline . & $\%$ & $\begin{array}{c}\text { moles } \times 10^{-8} \\
\text { malonylaldehyde } \\
\text { per ml } R B C\end{array}$ & \multicolumn{2}{|c|}{$\epsilon \times 10^{-3}$} \\
\hline \multicolumn{5}{|l|}{ Not incubated } \\
\hline \multicolumn{5}{|l|}{ Incubated in air } \\
\hline \multirow{5}{*}{$\begin{array}{l}\text { Incubated with } \mathrm{H}_{2} \mathrm{O}_{2} \text { diffusion } \ddagger \\
\quad+d l-\alpha \text {-Tocopherol, } 0.22 \mathrm{mg} \text { per } 100 \mathrm{ml} \\
\quad+\text { Glucose, } 200 \mathrm{mg} \text { per } 100 \mathrm{ml} \\
+\mathrm{NaNO}_{2}, 28 \mathrm{mg} \text { per } 100 \mathrm{ml} \\
+\mathrm{CO}, 10 \mathrm{ml} \text { per } 100 \mathrm{ml} \text { of atmosphere }\end{array}$} & 87.0 & 13.9 & 3.6 & 2.0 \\
\hline & 1.5 & 1.4 & & \\
\hline & 1.5 & 1.6 & & \\
\hline & 1.5 & 1.4 & & \\
\hline & 5.0 & 4.8 & & \\
\hline
\end{tabular}

* Data are averaged from two experiments with RBC from patient A.V. and one experiment with RBC from patient R.B. The hematocrit of the RBC suspension was 10\%. Exposure time was 4 to 6 hours.

$\dagger$ Lipids were extracted without 2,6-di-tert-butyl 4 methyl phenol.

$\ddagger \mathrm{In}$ all of the samples incubated with $\mathrm{H}_{2} \mathrm{O}_{2}$ diffusion alone, hemolysis was $>79.0 \%$, 2-thiobarbituric acid (TBA) $>12.3$, and absorbency at $234 \mathrm{~m} \mu>3.5$ and at $268 \mathrm{~m} \mu>1.9$. Values for normal controls are shown in Table II. 
TABLE II

Effect of vitamin E therapy of patients with abetalipoproteinemia on the sensitivity of their $\mathrm{RBC}$ to $\mathrm{H}_{2} \mathrm{O}_{2}$ in vitro

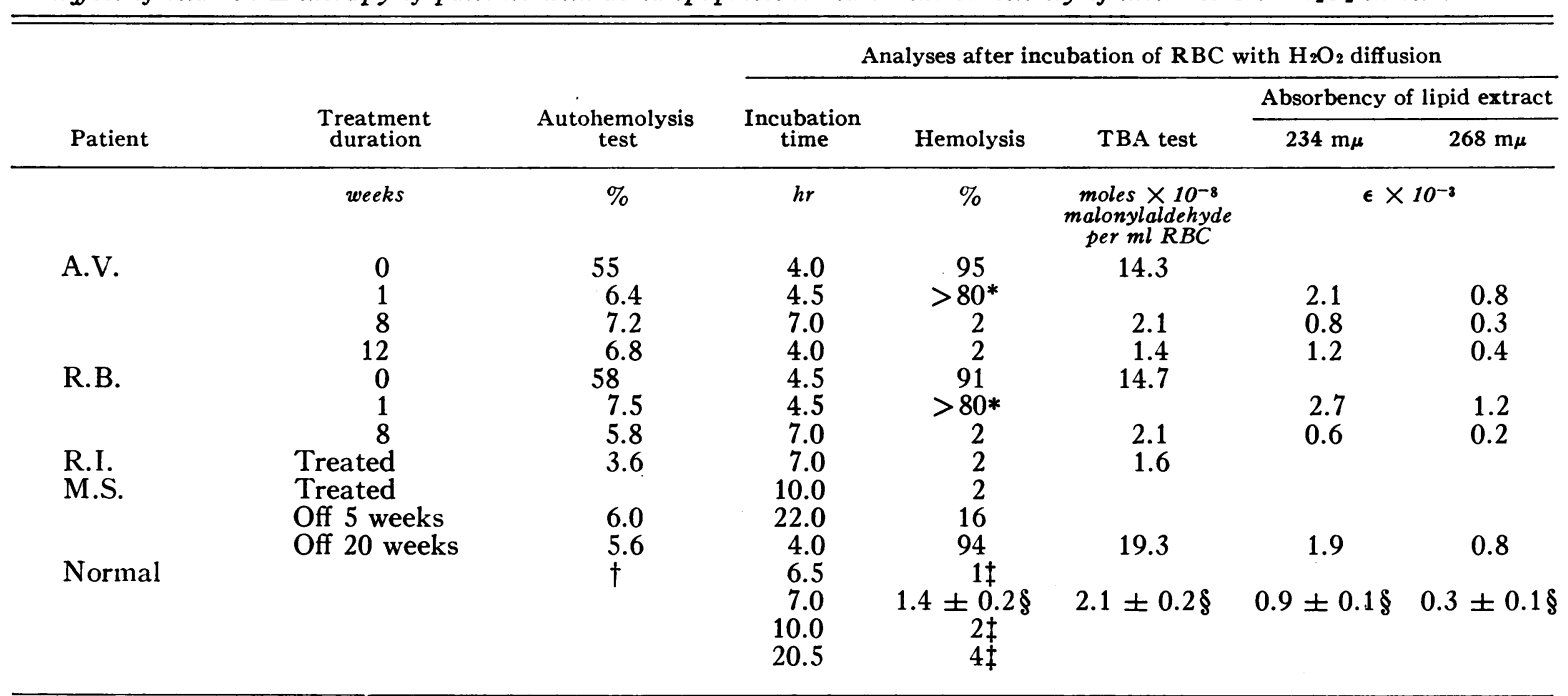

* Estimated by visual comparison.

t Normal values in this laboratory are $<4.5 \%$.

$\ddagger$ Averaged from two normal subjects; one was A.V.'s mother.

$\S$ Average \pm standard deviation from six normal subjects.

copherol-treated specimen was protected $(\mathrm{TBA}=$ $1.3 \times 10^{-8}$ mole of malonylaldehyde per $\mathrm{ml} \mathrm{RBC}$, hemolysis $=10 \%$ ), but the glucose-treated specimen had exhibited peroxidative hemolysis (TBA $=7.2 \times 10^{-8}$ mole, hemolysis $=84 \%$ ).

We provided further evidence for the importance of lipid peroxidation in the hemolysis observed on exposure of $\mathrm{RBC}$ from patients with abetalipoproteinemia to $\mathrm{H}_{2} \mathrm{O}_{2}$ in vitro by studying the effect of vitamin $\mathrm{E}$ therapy in four patients (Table II). The RBC from two patients, A.V. and R.B., were studied before and during the administration of vitamin $\mathrm{E}(d-\alpha$-tocopheryl polyethyleneglycol succinate) ${ }^{18}$ equivalent to $750 \mathrm{mg}$ of $\alpha$-tocopherol daily by mouth. Protection of the RBC against autohemolysis, but not $\mathrm{H}_{2} \mathrm{O}_{2}$, was noted after 1 week of therapy. After 8 weeks, the RBC were fully protected for at least 7 hours of exposure to $\mathrm{H}_{2} \mathrm{O}_{2}$. Maintenance of this improvement was documented for patient A.V. after 12 weeks of treatment. Two patients, R.I. and M.S., had received vitamin $\mathrm{E}$ in a variety of dosage forms when these tests were first performed. Their RBC gave normal responses to $\mathrm{H}_{2} \mathrm{O}_{2}$ in this system on incubation for 7 and 10 hours, respectively. Patient M.S. dis-

13 Provided by Dr. Stanley Ames, Distillation Products Industries, Rochester, N. Y. continued vitamin $\mathrm{E}$ therapy, and his $\mathrm{RBC}$ exhibited sensitivity to $\mathrm{H}_{2} \mathrm{O}_{2}$ when tested several months later; however, at that time his autohemolysis test was not strikingly abnormal.

The fatty acid and phospholipid distribution of the $\mathrm{RBC}$ from these patients during vitamin $\mathrm{E}$ therapy (38) was similar to that reported previously for untreated patients with abetalipoproteinemia $(15,18,39)$, suggesting that the protective effect of vitamin $E$ in these studies was not due to correction of the abnormal RBC lipid distribution. Vitamin $\mathrm{E}$ administered orally in a water-soluble form protected the RBC, even though tocopherol could not be determined in the plasma. This discrepancy may be explained either by increased plasma levels that were still below the useful range of the method employed ( $<0.08 \mathrm{mg}$ per $100 \mathrm{ml}$ ) or by increased tissue levels not reflected in the plasma because of the absence of beta lipoprotein, where most of the plasma tocopherol is found normally; tissue levels were not determined.

Sequential measurements of lysis and lipid peroxidation during exposure to $\mathrm{H}_{2} \mathrm{O}_{2}$ diffusion were carried out on the RBC of patient M.S., who had not received vitamin $\mathrm{E}$ for 6 months. The results from the two experiments done 4 weeks apart (experiments $A$ and $B$ ) are shown in Table III. The 
TABLE III

Sequential changes during exposure of $\mathrm{RBC}$ from an untreated patient ${ }^{*}$ with abetalipoproteinemia to $\mathrm{H}_{2} \mathrm{O}_{2}$ in vitro

\begin{tabular}{|c|c|c|c|c|c|c|c|c|c|}
\hline \multirow[b]{2}{*}{$\begin{array}{l}\text { Incubation time with } \mathrm{H}_{2} \mathrm{O}_{2} \text { diffusion } \\
\text { (hours) }\end{array}$} & \multicolumn{5}{|c|}{ Experiment A } & \multicolumn{4}{|c|}{ Experiment B } \\
\hline & 0.0 & 1.5 & 2.5 & 4.5 & 4.5 & 0.0 & 1.8 & 2.8 & 4.0 \\
\hline $\begin{array}{l}d l \text { - } \alpha \text {-Tocopherol added } \\
\quad(\mu g \text { per ml RBC suspension) }\end{array}$ & & & & & 2.5 & & & & \\
\hline Hemolysis $(\%)$ & 1 & 1 & 7 & 97 & 1 & 1 & 1 & 42 & 69 \\
\hline $\begin{array}{l}\text { 2-Thiobarbituric acid test (moles } \\
\left.\times 10^{-8} \text { malonylaldehyde } / \mathrm{ml} R B C\right)\end{array}$ & 1.4 & 2.0 & 6.9 & 11.9 & 1.6 & 1.3 & 1.9 & 8.5 & 12.7 \\
\hline $\begin{array}{l}\text { Absorbency of total lipid }\left(\epsilon \times 10^{-3}\right) \\
234 \mathrm{~m} \mu \\
268 \mathrm{~m} \mu\end{array}$ & & & & & & $\begin{array}{l}0.88 \\
0.33\end{array}$ & $\begin{array}{l}0.95 \\
0.35\end{array}$ & $\begin{array}{l}1.35 \\
0.53\end{array}$ & $\begin{array}{l}1.75 \\
0.75\end{array}$ \\
\hline \multicolumn{10}{|c|}{ Fatty acid distribution in total phospholipid $\dagger$ (weight \%) } \\
\hline $\begin{array}{l}16: 0 \\
18: 0+18: 1 \text { aldehyde } \S \\
18: 1 \\
18: 2 \\
20: 3 \omega 6+22: 0 \\
20: 4 \omega 6+22: 1 \| \\
24: 0 \\
22: 4 \omega 6+24: 1 \rrbracket \\
22: 5 \omega 6 \\
24: 2 \\
22: 5 \omega 3 \\
22: 6 \omega 3+26: 0^{* *} \\
\text { Sum of } 10 \text { minor peaks }\end{array}$ & $\begin{array}{r}20.2 \\
16.1 \\
10.7 \\
2.8 \\
2.8 \\
14.5 \\
3.6 \\
13.2 \\
2.6 \\
1.4 \\
2.3 \\
4.0 \\
5.8\end{array}$ & $\begin{array}{r}20.2 \ddagger \\
16.5 \\
10.4 \\
2.8 \\
2.1 \\
12.7 \\
3.8 \\
12.6 \\
2.0 \\
1.1 \\
2.0 \\
4.5 \\
4.5\end{array}$ & $\begin{array}{r}20.2 \ddagger \\
15.1 \\
10.0 \\
2.6 \\
2.2 \\
11.6 \\
3.6 \\
12.6 \\
1.9 \\
1.2 \\
1.7 \\
3.2 \\
5.1\end{array}$ & $\begin{array}{r}20.2 \ddagger \\
10.6 \\
8.8 \\
2.2 \\
2.0 \\
5.4 \\
4.0 \\
10.3 \\
0.7 \\
1.1 \\
0.7 \\
1.2 \\
3.9\end{array}$ & $\begin{array}{r}20.6 \\
17.0 \\
10.8 \\
2.7 \\
2.5 \\
14.4 \\
3.7 \\
13.2 \\
2.5 \\
1.3 \\
2.4 \\
3.9 \\
5.0\end{array}$ & $\begin{array}{r}20.7 \\
17.3 \\
10.7 \\
2.7 \\
2.4 \\
14.7 \\
3.6 \\
13.3 \\
2.3 \\
1.2 \\
2.2 \\
4.0 \\
4.9\end{array}$ & & & $\begin{array}{r}20.7 \ddagger \\
13.0 \\
10.0 \\
2.2 \\
2.2 \\
6.8 \\
4.8 \\
13.2 \\
1.2 \\
1.6 \\
1.3 \\
1.8 \\
4.0\end{array}$ \\
\hline Total & 100.0 & 95.2 & 91.0 & 71.1 & 100.0 & 100.0 & & & 82.8 \\
\hline \multicolumn{10}{|l|}{ Phospholipid distribution $\dagger \dagger$ (molar \%) } \\
\hline \multicolumn{5}{|l|}{$\begin{array}{l}\text { Phosphatidyl ethanolamine }+ \text { polygl } \\
\text { Phosphatidyl serine } \\
\text { Phosphatidyl inositol } \ddagger \\
\text { Phosphatidyl choline } \\
\text { Sphingomyelin } \\
\text { Lysophosphatidyl choline } \\
\text { Origin }\end{array}$} & & $\begin{array}{r}30.4 \\
16.8 \\
0.2 \\
18.7 \\
33.7 \\
0.2 \\
0.0\end{array}$ & & & $\begin{array}{r}15.5 \\
10.1 \\
2.5 \\
17.4 \\
33.6 \\
0.8 \\
0.5\end{array}$ \\
\hline Total & & & & & & 100.0 & & & 80.4 \\
\hline
\end{tabular}

* Patient M.S., who had not received vitamin $E$ for 6 months before experiment $A$ and 7 months before experiment $B$. $\dagger$ In this abbreviation of the fatty acids, the first two digits state the number of carbon atoms, the third digit states the number of double bonds, and the digit after the omega states the end carbon chain length.

† The fatty acid percentages in these incubated samples were recalculated by means of the factor that made the per cent of palmitic acid equal to its value in the control sample.

\& The dimethyl acetal was eluted with this peak and accounted for $12 \%$ of the area in control samples; this component remained after exposure to $\mathrm{H}_{2} \mathrm{O}_{2}$.

I| $22: 1$ accounted for $3 \%$ of this peak in control samples.

T $24: 1$ accounted for $55 \%$ of this peak in control samples.

** 26:0 accounted for $9 \%$ of this peak in control samples.

†† Based on the per cent of phosphorus in each spot on thin layer chromatography. Only $80.4 \%$ of the lipid phosphorus of the control RBC was obtained in the lipid extract of cells that were exposed to $\mathrm{H}_{2} \mathrm{O}_{2}$.

\# Not positively identified.

data from experiment A suggest that lipid changes preceded lysis, as 1 ) the relative amount of arachidonic acid $(20: 4 \omega 6)$ was decreased $12 \%$ after 1.5 hours of incubation, although no abnormal hemolysis was evident; and 2) the TBA reaction was increased $58 \%$ of the maximal value after 2.5 hours, when hemolysis was only $7 \%$. The temporal relationship between parameters of lipid peroxidation and hemolysis for experiment $A$ is diagrammed in Figure 2. In experiment B, lysis had already proceeded too far at 2.8 hours, and the temporal relationship could not be determined.

The distribution of the individual phospholipids was analyzed in experiment B (Table III). The lipid phosphorus content of the extract of incubated RBC was only $80.4 \%$ of the control value. This finding along with the low values for phosphatidyl ethanolamine (PE) and phosphatidyl 


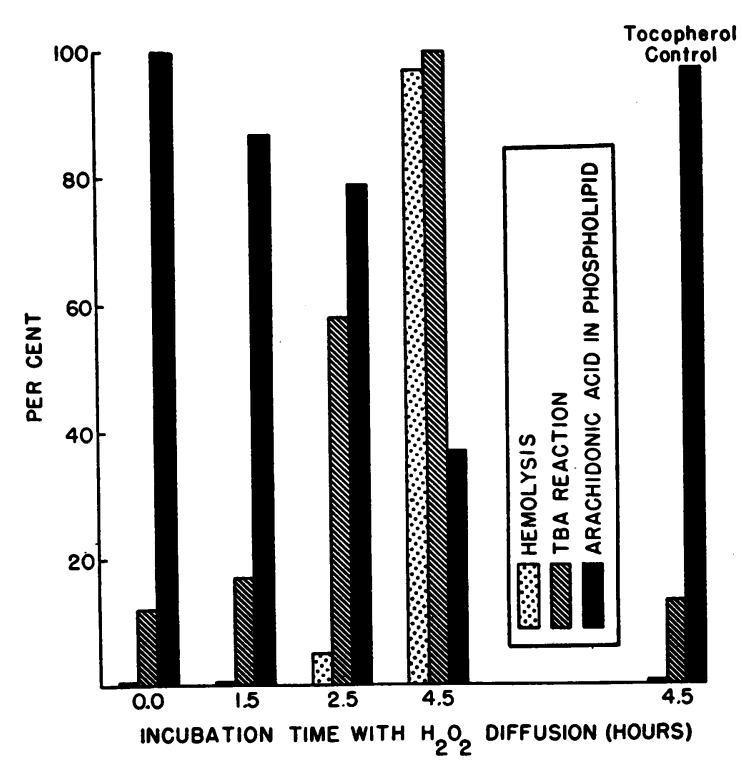

Fig. 2. EFFECTS OF EXPOSURE OF RBC FROM AN UNTREATED PATIENT WITH ABETALIPOPROTEINEMIA (M.S.) TO $\mathrm{H}_{2} \mathrm{O}_{2}$ IN vitro, DiagramMEd FROM DATA IN TABLE III, EXPERIMENT A. Per cent TBA reaction refers to per cent of 2-thiobarbituric acid reaction at 4.5 hours, and per cent arachidonic acid to per cent of value at 0 time.

serine (PS) suggested that most of the missing $\mathrm{PE}$ and $\mathrm{PS}$ was not extracted from the $\mathrm{RBC}$ or was removed by the washing procedure. This interpretation was supported by the observation of a decreased amount of Ninhydrin staining on the TLC plate. A small amount of Ninhydrin staining in the region of phosphatidyl inositol indicated that the apparent increase shown for that moiety probably represented peroxidized "cephalin" that trailed during chromatography. Large decreases were observed in the relative concentrations of the polyunsaturated fatty acids (Table III). The large amount of arachidonic acid normally present in $\mathrm{RBC}$ made it the most useful polyunsaturated fatty acid to quantify as an index of the $\mathrm{H}_{2} \mathrm{O}_{2}$ effect. The relative concentration of stearic acid (18:0), however, also showed a large decrease. The decrease of this saturated fatty acid probably was related to the decreased phospholipid in the lipid extract after exposure of the $\mathrm{RBC}$ to $\mathrm{H}_{2} \mathrm{O}_{2}$. The stearic acid of human RBC is found mainly in PE and PS and is by far the most abundant fatty acid in the latter phospholipid $(31,40,41)$; loss of cephalin from the lipid extract, therefore, may account for a decrease of stearic acid.

Because the decreased extraction of peroxidized phospholipid may influence results of fatty acid analyses of lipid extracts, the fatty acid composition of the total lipid in the incubation suspension was determined without prior extraction. This was accomplished by acid hydrolysis of the RBC suspension, conversion of the fatty acids to methyl esters, and GLC of these derivatives. The results indicated that mainly the polyunsaturated fatty acids were affected by exposure of the RBC to $\mathrm{H}_{2} \mathrm{O}_{2}$ (Table IV). The decrease of a given fatty acid moiety appeared to be related to the number of double bonds that it contained. The decrease of the peak that contained the polyunsaturated fatty acid $22: 4 \omega 6$ probably would have been larger if the peak did not also contain a large amount of nervonic acid $(24: 1)$. By this method of analysis, stearic acid $(18: 0)$ was decreased only $7 \%$.

To assess further the role of vitamin $\mathrm{E}$ deficiency in the $\mathrm{RBC}$ alterations observed, the RBC from vitamin $\mathrm{E}$-deficient rats were tested in the same manner. The RBC changes that occurred (Table V) were similar to those seen with $\mathrm{RBC}$

TABLE IV

The effect of $\mathrm{H}_{2} \mathrm{O}_{2}$ exposure on the $\mathrm{RBC}$ total lipid fatty acid distribution determined without prior extraction*

\begin{tabular}{lll}
\hline \hline & \multicolumn{2}{l}{ RBC sample } \\
\cline { 2 - 3 } & 0 & 4.0 hours \\
Incubation time exposed to $\mathrm{H}_{2} \mathrm{O}_{2}$ & 0
\end{tabular}

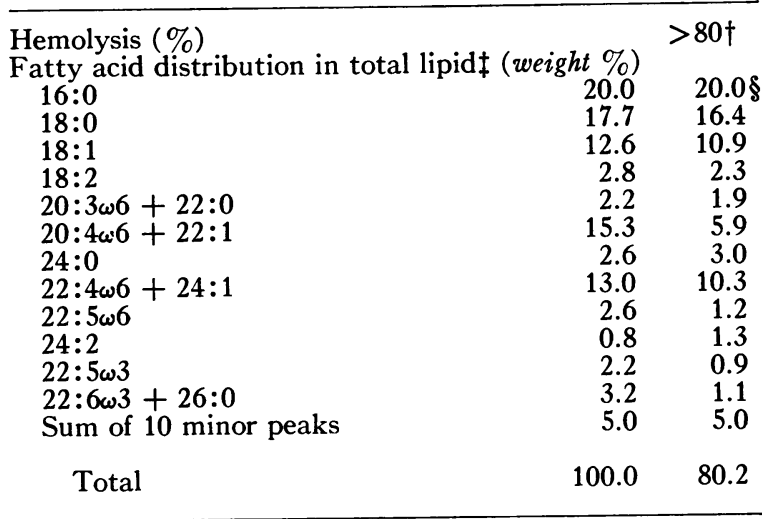

* The RBC were from patient M.S., who had not received vitamin $E$ for 7 months before this study.

$\dagger$ Estimated by visual comparison.

¥ Fatty acid methyl esters were prepared by aqueous $\mathrm{HCl}$ hydrolysis of the incubation suspension followed by methylation of the extracted fatty acids (see text). Explanation for abbreviations of the fatty acids is given in footnote to Table III.

$\$$ The fatty acid percentages in the incubated sample were recalculated to make the per cent of palmitic acid equal to that of the control sample. 
TABLE V

Effect of exposure of $\mathrm{RBC}$ from vitamin $\mathrm{E}$-deficient rats to $\mathrm{H}_{2} \mathrm{O}_{2}$ in vitro*

\begin{tabular}{|c|c|c|c|c|c|c|c|c|}
\hline \multirow[b]{2}{*}{ Incubation time with $\mathrm{H}_{2} \mathrm{O}_{2}$ diffusion (hours) } & \multicolumn{6}{|c|}{ Experiment A } & \multicolumn{2}{|c|}{ Experiment B } \\
\hline & 0.0 & 0.3 & 0.7 & 1.3 & 2.0 & 2.0 & 0.0 & 1.5 \\
\hline$d l$ - $\alpha$-Tocopherol added ( $\mu g$ per $m l R B C$ suspension) & & , & & & & 7.5 & & \\
\hline Hemolysis $(\%)$ & 9 & 9 & 12 & 54 & 93 & 11 & 6 & 91 \\
\hline $\begin{array}{l}\text { 2-Thiobarbituric acid test (moles } \times 10^{-8} \text { malonyl- } \\
\text { aldehyde } / \text { ml } R B C \text { ) }\end{array}$ & 1.3 & 2.0 & 3.8 & 15.1 & 14.3 & 1.2 & 1.2 & 16.4 \\
\hline \multicolumn{9}{|l|}{ Fatty acid distribution in total phospholipid $\dagger$ (weight \%) } \\
\hline $\begin{array}{l}16: 0 \\
18: 0+18: 1 \text { aldehyde } \\
18: 1 \\
18: 2 \\
20: 4 \omega 6+22: 1 \\
24: 0 \\
22: 4 \omega 6+24: 1 \\
22: 5 \omega 6 \\
24: 2 \\
22: 5 \omega 3 \\
22: 6 \omega 3+26: 0 \\
\text { Sum of } 11 \text { minor peaks }\end{array}$ & & & & & & & $\begin{array}{r}25.0 \\
15.7 \\
11.7 \\
5.7 \\
24.5 \\
1.6 \\
5.9 \\
1.3 \\
0.3 \\
0.6 \\
1.7 \\
6.0\end{array}$ & $\begin{array}{l}25.0 \ddagger \\
12.6 \\
10.5 \\
5.0 \\
9.9 \\
1.7 \\
4.6 \\
0.6 \\
0.4 \\
0.3 \\
0.7 \\
4.1\end{array}$ \\
\hline Total & & & & & & & 100.0 & 75.4 \\
\hline \multicolumn{9}{|l|}{ Phospholipid distribution $\S($ molar $\%$ ) } \\
\hline $\begin{array}{l}\text { Phosphatidyl ethanolamine + polyglycerolphosphatide\|l } \\
\text { Phosphatidyl serine } \\
\text { Phosphatidyl inositol\| } \\
\text { Phosphatidyl choline } \\
\text { Sphingomyelin } \\
\text { Lysophosphatidyl choline } \\
\text { Origin }\end{array}$ & & & & & & & $\begin{array}{r}24.0 \\
11.6 \\
5.4 \\
42.1 \\
13.1 \\
3.6 \\
0.2\end{array}$ & $\begin{array}{r}12.7 \\
6.7 \\
7.3 \\
41.1 \\
15.3 \\
5.4 \\
1.5\end{array}$ \\
\hline Total & & & & & & & 100.0 & 90.0 \\
\hline
\end{tabular}

* The hematocrit of the RBC suspension was between 30 and $40 \%$, as in the comparable experiments with human RBC (Table III).

t Explanation for abbreviations of the fatty acids is given in footnote to Table III.

$\ddagger$ The fatty acid percentages in the incubated sample were recalculated to make the per cent of palmitic acid equal to that of the control sample.

$\$$ Only $90 \%$ of the RBC lipid phosphorus in the control sample was obtained in the lipid extract of cells that were exposed to $\mathrm{H}_{2} \mathrm{O}_{2}$. The individual phospholipids were identified only by mobility on the thin layer plate.

|| Not positively identified.

from the patient with abetalipoproteinemia. Lipid peroxidation again appeared to precede hemolysis ; at 0.7 hour the TBA reaction was elevated, but hemolysis was not increased significantly. Considerable hemolysis was evident, however, before $\mathrm{H}_{2} \mathrm{O}_{2}$ exposure, and the hemolysis proceeded at a more rapid rate.

Alpha-tocopherol, when added to the incubation medium before exposure to $\mathrm{H}_{2} \mathrm{O}_{2}$, prevented all of the changes observed in the $\mathrm{RBC}$ of patients with abetalipoproteinemia (Tables I and III) and of rats with vitamin $\mathrm{E}$ deficiency (Table $\mathrm{V}$ ).

\section{Discussion}

The present study demonstrates the striking vulnerability to $\mathrm{H}_{2} \mathrm{O}_{2}$ of $\mathrm{RBC}$ from untreated pa- tients with abetalipoproteinemia, as evidenced by lipid peroxidation and hemolysis (peroxidative hemolysis). The lipid peroxidation was similar to that seen in spontaneously autoxidized lipid extracts from normal human RBC (2). Vitamin $E$ deficiency appeared to be responsible for this vulnerability, as 1) the patients were shown to be deficient in vitamin $E, 2$ ) vitamin $E$ is a major biologic lipid antioxidant, 3) administration of vitamin $\mathrm{E}$ to the patients or addition to the RBC in vitro prevented peroxidative hemolysis, and 4) the $\mathrm{RBC}$ damage in response to $\mathrm{H}_{2} \mathrm{O}_{2}$ could be duplicated in $\mathrm{RBC}$ from vitamin $\mathrm{E}$-deficient rats.

Rose and György were the first to describe the increased hemolysis of RBC from vitamin E-de- 
ficient rats upon exposure to $\mathrm{H}_{2} \mathrm{O}_{2}$ added directly in vitro; administration of the vitamin in vivo or addition to the RBC suspension in vitro, furthermore, prevented hemolysis (42). Slight modifications of their method for $\mathrm{H}_{2} \mathrm{O}_{2}$ exposure have been used for evaluation of vitamin $\mathrm{E}$ levels in premature infants $(43,44)$, newborn full-term infants $(44,45)$, and children and adults in a variety of clinical circumstances that includes dietary alterations $(5,11,44,46)$ and malabsorption syndromes $(12,44,46)$. In the present study, minute amounts of $\mathrm{H}_{2} \mathrm{O}_{2}$ were added by continuous diffusion into a suspension of $\mathrm{RBC}$ during incubation as described by Cohen and Hochstein (25, 26); this method provides an approximation to the continuous formation of $\mathrm{H}_{2} \mathrm{O}_{2}$ as it might occur under physiologic conditions. The amount of $\mathrm{H}_{2} \mathrm{O}_{2}$ required for hemolysis in this system was approximately three orders of magnitude smaller than in the direct $\mathrm{H}_{2} \mathrm{O}_{2}$ addition test described by Rose and György (42). The low levels of $\mathrm{H}_{2} \mathrm{O}_{2}$ provided by the diffusion system have helped to elucidate the importance of the enzyme glutathione peroxidase as a primary defense mechanism of RBC against the minute amounts of $\mathrm{H}_{2} \mathrm{O}_{2}$ that may arise in vivo from the action of certain hemolytic drugs $(26,47-49)$. This $\mathrm{H}_{2} \mathrm{O}_{2}$ diffusion system was employed in these studies of patients with abetalipoproteinemia to demonstrate the possible consequences of deficiency of vitamin $\mathrm{E}$, another primary biologic defense against peroxidative stress.

Previous studies have shown that hemolysis on exposure to $\mathrm{H}_{2} \mathrm{O}_{2}$ of $\mathrm{RBC}$ from vitamin E-deficient man (5) and animals $(4,6)$ is accompanied by an increase in the TBA reaction of the lysate. It was also shown that replacement of vitamin $\mathrm{E}$ in vivo by oral or parenteral routes, or addition of the vitamin to the incubation suspension before exposure to $\mathrm{H}_{2} \mathrm{O}_{2}$, prevented the increase in the TBA reaction as well as the hemolysis (4-6). The protection afforded by vitamin $\mathrm{E}$ appears to be based on its antioxidant properties, because lipid-soluble antioxidants that are not of biologic origin protect vitamin $\mathrm{E}$-deficient $\mathrm{RBC}$ during exposure to $\mathrm{H}_{2} \mathrm{O}_{2}$ in vitro (5). These lines of evidence have suggested that peroxidation of lipids may be an important factor in the hemolysis of vitamin E-deficient $\mathrm{RBC}$ on exposure to $\mathrm{H}_{2} \mathrm{O}_{2}$.

Evidence for lipid peroxidation in the present study is based on analyses of the ultraviolet light absorbency and the fatty acid composition of lipid extracts of the incubation suspension, as well as on the results of the TBA test and the protective effect of vitamin $\mathrm{E}$ in vitro and in vivo. Increases in ultraviolet light absorbency paralleled the increase in the TBA reaction. The increased absorbencies at 234 and $268 \mathrm{~m} \mu$ are consistent with the appearance of conjugated dienes and conjugated trienes, respectively, which are well-established intermediate structures formed during autoxidation of polyunsaturated fatty acids (30). Fatty acid analyses showed a decrease in unsaturated moieties that appeared to be proportional to their number of double bonds. The rates of fatty acid autoxidation have been reported to be many times greater for polyunsaturated than for saturated moieties (50). A similar hierarchy for the susceptibility of tissue lipids based on their degree of unsaturation was shown for heme-catalyzed peroxidation $(9,51)$.

Evidence was obtained supporting a hypothesis that peroxidation of membrane lipids is the basis for hemolysis on exposure to $\mathrm{H}_{2} \mathrm{O}_{2}$ in vitro of $\mathrm{RBC}$ from patients with abetalipoproteinemia and vitamin $\mathrm{E}$ deficiency. A time sequence study showed a decrease in the relative amount of phospholipid arachidonic acid before abnormal hemolysis occurred and a large increase in the TBA reaction when hemolysis was starting. Similar TBA changes were observed in the RBC from vitamin E-deficient rats. All procedures tested that prevented peroxidation in vitro (i.e., addition to the incubation system of tocopherol, glucose, nitrite, or carbon monoxide) also prevented hemolysis. Finally, after treatment of the patients with vitamin $\mathrm{E}$, their $\mathrm{RBC}$ showed increased resistance to $\mathrm{H}_{2} \mathrm{O}_{2}$ in vitro. This effect was presumably due to the antioxidant properties of the vitamin rather than to some possible secondary influence of the vitamin, such as a change in the abnormal distribution of phospholipids and fatty acids in their RBC, because detailed analyses of RBC lipids performed concurrently with this study showed no correction of the altered lipid distribution as a result of treatment with vitamin $\mathrm{E}$ (38).

Heme-containing compounds have been recognized as important catalysts of lipid peroxidation in various animal tissues (9). Lipid peroxidation in $\mathrm{RBC}$ from patients with abetalipoproteinemia 
appeared to be catalyzed primarily by either oxyor deoxyhemoglobin, because nitrite and carbon monoxide, which produced methemoglobin or carboxyhemoglobin, respectively, inhibited peroxidation. These findings were in agreement with those of Goldstein and Cohen on RBC from vitamin E-deficient rats (6).

The partial protection of RBC from patients with abetalipoproteinemia by addition of glucose to the incubation suspension may be explained by the action of glutathione peroxidase, which catalyzes the destruction of $\mathrm{H}_{2} \mathrm{O}_{2}$ after it diffuses into the cell (24). In the absence of glucose, the protective glutathione is lost by oxidation; in the presence of glucose, the NADPH required for reduction of oxidized glutathione is derived from hexose monophosphate shunt activity. Tocopherol, however, protected for a longer incubation time than glucose, in agreement with similar observations with RBC from vitamin E-deficient rats (6). These findings indicate that tocopherol provides a primary biologic defense against peroxidative hemolysis.

Anemia is not generally found in patients with abetalipoproteinemia; however, Simon and Ways (16) and Farquhar and Ways (52) have presented evidence and have summarized the work of others that strongly suggests that intermittent hemolysis may occur. Although the causes of this hemolysis have not been defined, $\mathrm{H}_{2} \mathrm{O}_{2}$ formed in vivo, such as by Mycoplasma pneumoniae or $M$. laidlawii $(53,54)$, 8-aminoquinoline antimalarials $(47)$, or menadione $(47,48)$, may be responsible. Aspirin, phenacetin, and sulfonamides are examples of other drugs that have, in theory, this same capability (47). In addition, exposure of vitamin E-deficient animals to hyperbaric oxygen causes a hemolytic response (4), which appears from recent evidence to be based on peroxidation of membrane lipids (8). Therefore, treatment of patients with abetalipoproteinemia with $\mathrm{H}_{2} \mathrm{O}_{2}$-producing drugs or hyperbaric oxygen should be approached with caution.

Should peroxidative changes occur in the lipids of $\mathrm{RBC}$ in vivo, the clinical manifestations may be tempered by that cell's considerable capacity for replacement. In contrast, the nervous system exhibits greater functional differentiation with limited regenerative capacity and has low levels of the protective enzymes glutathione peroxidase and catalase (55). Lipid peroxidation of this tissue may be expected to produce diverse and cumulative changes. Indeed, vitamin $\mathrm{E}$ deficiency in laboratory animals is associated with characteristic neurological and neuropathological finding (56-58). A major disability in abetalipoproteinemia is a progressive neurologic disorder (52, 59). The possibility arises, therefore, that the neurologic as well as other clinical manifestations in patients with abetalipoproteinemia may result from lipid peroxidation.

\section{Acknowledgments}

The technical assistance of Carole Rockmore, Cathy Berzin, Mildred Medick, Dorothy Dembiec, and Judith Marcus is gratefully acknowledged.

\section{References}

1. Dodge, J. T., G. Cohen, H. J. Kayden, and G. B. Phillips. Peroxidation of membrane lipids: a mechanism for cell damage in acanthocytosis ( $\beta$-lipoprotein deficiency) (abstract). J. clin. Invest. $1966,45,1000$.

2. Dodge, J. T., and G. B. Phillips. Autoxidation as a cause of altered lipid distribution in extracts from human red cells. J. Lipid Res. 1966, 7, 387.

3. Tsen, C. C., and H. B. Collier. The protective action of tocopherol against hemolysis of rat erythrocytes by dialuric acid. Canad. J. Biochem. 1960, 38, 957.

4. Mengel, C. E., H. E. Kann, Jr., W. W. Smith, and B. D. Horton. Effects of in vivo hyperoxia on erythrocytes. I. Hemolysis in mice exposed to hyperbaric oxygenation. Proc. Soc. exp. Biol. (N. Y.) 1964, 116, 259.

5. Horwitt, M. K., C. C. Harvey, G. D. Duncan, and W. C. Wilson. Effects of limited tocopherol intake in man with relationships to erythrocyte hemolysis and lipid oxidations. Amer. J. clin. Nutr. 1956, 4, 408.

6. Goldstein, H. B., and G. Cohen. In preparation.

7. Bunyan, J., J. Green, E. E. Edwin, and A. T. Diplock. Studies on vitamin E. 5. Lipid peroxidation in dialuric acid-induced haemolysis of vitamin E-deficient erythrocytes. Biochem. J. 1960, 77, 47.

8. Mengel, C. E., and H. E. Kann, Jr. Effects of in vivo hyperoxia on erythrocytes. III. In vivo peroxidation of erythrocyte lipid. J. clin. Invest. 1966, 45, 1150.

9. Tappel, A. L. Biocatalysts : lipoxidase and hematin compounds in Autoxidation and Antioxidants, W. O. Lundberg, Ed. New York, Interscience, 1961, vol. 1 , p. 325 .

10. Aaes-J $\phi$ rgensen, E. Autoxidation of fatty compounds in living tissue, biological antioxidants in 
Autoxidation and Antioxidants, W. O. Lundberg, Ed. New York, Interscience, 1961, vol. 2, p. 1045.

11. Horwitt, $M$. K. Interrelations between vitamin $E$ and polyunsaturated fatty acids in adult men. Vitam. and Horm. 1962, 20, 541.

12. Binder, H. J., D. C. Herting, V. Hurst, S. C. Finch, and H. M. Spiro. Tocopherol deficiency in man. New Engl. J. Med. 1965, 273, 1289.

13. Kayden, H. J., and R. Silber. The role of vitamin E deficiency in the abnormal autohemolysis of acanthocytosis. Trans. Ass. Amer. Phycns 1965, 78, 334.

14. Wolff, J. A., and W. A. Bauman. Studies concerning acanthocytosis: a new genetic syndrome with absent beta lipoprotein (abstract). Amer. J. Dis. Child. 1961, 102, 478.

15. Phillips, G. B. Quantitative chromatographic analysis of plasma and red blood cell lipids in patients with acanthocytosis. J. Lab. clin. Med. 1962, 59, 357.

16. Simon, E. R., and P. Ways. Incubation hemolysis and red cell metabolism in acanthocytosis. J. clin. Invest. 1964, 43, 1311.

17. Ways, P., and E. R. Simon. The role of serum in acanthocyte autohemolysis and membrane lipid composition. J. clin. Invest. 1964, 43, 1322.

18. Ways, P., C. F. Reed, and D. J. Hanahan. Red-cell and plasma lipids in acanthocytosis. J. clin. Invest. $1963,42,1248$.

19. Schwartz, J. F., L. P. Rowland, H. Eder, P. A. Marks, E. F. Osserman, E. Hirschberg, and H. Anderson. Bassen-Kornzweig syndrome: deficiency of serum $\beta$-lipoprotein. Arch. Neurol. (Chic.) 1963, 8, 438.

20. Isselbacher, K. J., R. Scheig, G. R. Plotkin, and J. B. Caulfield. Congenital $\beta$-lipoprotein deficiency: an hereditary disorder involving a defect in the absorption and transport of lipids. Medicine (Baltimore) 1964, 43, 347.

21. Levy, R. I., D. S. Fredrickson, and L. Laster. The lipoproteins and lipid transport in abetalipoproteinemia. J. clin. Invest. 1966, 45, 531.

22. Quaif, M. L., N. S. Scrimshaw, and O. H. Lowry. A micromethod for assay of total tocopherols in blood serum. J. biol. Chem. 1949, 180, 1229.

23. Young, L. E., M. J. Izzo, K. I. Altman, and S. N. Swisher. Studies on spontaneous in vitro autohemolysis in hemolytic disorders. Blood 1956, 11, 977.

24. Dacie, J. V., and S. M. Lewis. Practical Haematology, 3rd ed. London, J. \& A. Churchill, 1963, p. 136.

25. Cohen, G., and P. Hochstein. Glucose-6-phosphate dehydrogenase and detoxification of hydrogen peroxide in human erythrocytes. Science 1961, 134, 1756.

26. Cohen, G., and P. Hochstein. Glutathione peroxidase : the primary agent for the elimination of hydrogen peroxide in erythrocytes. Biochemistry 1963, 2, 1420.
27. Bernheim, F., M. L. C. Bernheim, and K. M. Wilbur. The reaction between thiobarbituric acid and the oxidation products of certain lipides. J. biol. Chem. 1948, 174, 257.

28. Dahle, L. K., E. G. Hill, and R. T. Holman. The thiobarbituric acid reaction and the autoxidations of polyunsaturated fatty acid methyl esters. Arch. Biochem. 1962, 98, 253.

29. Phillips, M. A., and R. D. Hinkel. Determination of 2,6-di-tert-butyl-p-cresol in edible fats by ultraviolet spectrophotometry. J. agricul. Fd Chem. 1957, 5, 379.

30. Link, W. E., and M. W. Formo. Analysis of autoxidation mixtures in Autoxidation and Antioxidants, W. O. Lundberg, Ed. New York, Interscience, 1961 , vol. 1, p. 367 .

31. Dodge, J. T., and G. B. Phillips. The distribution of the individual phospholipids, the total phospholipid fatty acids and aldehydes, and the individual phospholipid fatty acids of human red cells. Submitted for publication.

32. Skipski, V. P., R. F. Peterson, and M. Barclay. Quantitative analysis of phospholipids by thinlayer chromatography. Biochem. J. 1964, 90, 374.

33. Wren, J. J., and A. D. Szczepanowska. Chromatography of lipids in presence of an antioxidant, 4-methyl-2,6-di-tert-butylphenol. J. Chromatogr. 1964, 14, 405.

34. Morrison, W. R., and L. M. Smith. Preparation of fatty acid methyl esters and dimethylacetals from lipids with boron fluoride-methanol. J. Lipid Res. 1964, 5, 600.

35. Ackman, R. G., and R. D. Burgher. A proposed basis for the systematic identification of unsaturated fatty acid esters through gas-liquid chromatography on polyester substrates. J. Chromatogr. 1963, 11, 185.

36. Ackman, R. G., and R. D. Burgher. Cod liver oil fatty acids as secondary reference standards in the GLC of polyunsaturated fatty acids of animal origin : analysis of a dermal oil of the Atlantic leatherback turtle. J. Amer. Oil chem. Soc. 1965, 42, 38.

37. Mangold, H. K. Separation of lipids according to their degree of unsaturation in Thin-Layer Chromatography, E. Stahl, Ed. New York, Academic Press, 1965, p. 174.

38. Phillips, G. B., and J. T. Dodge. In preparation.

39. Farquhar, J. W., and E. H. Ahrens, Jr. Effects of dietary fats on human erythrocyte fatty acid patterns. J. clin. Invest. 1963, 42, 675.

40. Farquhar, J. W. Human erythrocyte phosphoglycerides. I. Quantification of plasmalogens, fatty acids, and fatty aldehydes. Biochim. biophys. Acta (Amst.) 1962, 60, 80.

41. Ways, P., and D. J. Hanahan. Characterization and quantification of red cell lipids in normal man. J. Lipid Res. 1964, 5, 318.

42. Rose, C. S., and P. György. Specificity of hemolytic reaction in vitamin E-deficient erythrocytes. Amer. J. Physiol. 1952, 168, 414. 
43. Gordon, H. H., and J. P. de Metry. Hemolysis in hydrogen peroxide of erythrocytes of premature infants. Effect of alpha-tocopherol. Proc. Soc. exp. Biol. (N. Y.) 1952, 79, 446.

44. Gordon, H. H., H. M. Nitowsky, and M. Cornblath. Studies of tocopherol deficiency in infants and children. I. Hemolysis of erythrocytes in hydrogen peroxide. Amer. J. Dis. Child. 1955, 90, 669.

45. György, P., G. Cogan, and C. S. Rose. Availability of vitamin $E$ in the newborn infant. Proc. Soc. exp. Biol. (N. Y.) 1952, 81, 536.

46. Nitowsky, H. M., M. Cornblath, and H. H. Gordon. Studies of tocopherol deficiency in infants and children. II. Plasma tocopherol and erythrocyte hemolysis in hydrogen peroxide. J. Dis. Child. 1956, 92, 164.

47. Cohen, G., and P. Hochstein. Generation of hydrogen peroxide in erythrocytes by hemolytic agents. Biochemistry 1964, 3, 895.

48. Cohen, G., and P. Hochstein. In rivo generation of $\mathrm{H}_{2} \mathrm{O}_{2}$ in mouse erythrocytes by hemolytic agents. J. Pharmacol. exp. Ther. 1965, 147, 139.

49. Cohen, G. On the generation of hydrogen peroxide in erythrocytes by acetylphenylhydrazine. Biochem. Pharmacol. 1966, 15, 1775.

50. Swern, D. Primary products of olefinic autoxidations in Autoxidation and Antioxidants, W. O. Lundberg, Ed. New York, Interscience, 1961, vol. 1, p. 1.

51. Tappel, A. L., W. D. Brown, H. Zalkin, and V. P. Maier. Unsaturated lipid peroxidation catalyzed by hematin compounds and its inhibition by vitamin $\mathrm{E}$. J. Amer. Oil chem. Soc. 1961, 38, 5.

52. Farquhar, J. W., and P. Ways. Abetalipoproteinemia in The Metabolic Basis of Inherited Disease, 2nd. ed. J. B. Stanbury, J. B. Wyngaarden, and D. S. Fredrickson, Ed. New York, McGraw-Hill, 1966, p. 509.

53. Somerson, N. L., B. E. Walls, and R. M. Chanock. Hemolysin of Mycoplasma pneumoniae: tentative identification as a peroxide. Science 1965, 150, 226.

54. Cohen, G., and N. L. Somerson. Mycoplasma pneumonia: hydrogen peroxide secretion and its possible role in virulence. Ann. N. Y. Acad. Sci. In press.

55. Cohen, G., and P. Hochstein. Enzymatic mechanisms of drug sensitivity in brain. Dis. nerv. Syst. (suppl.) 1963, 24, 44.

56. Pentschew, A., and K. Schwarz. Systemic axonal dystrophy in vitamin $\mathrm{E}$ deficient adult rats, with implications in human neuropathology. Acta neuropath. (Berl.) 1962, 1, 313.

57. Lampert, P., J. M. Blumberg, and A. Pentschew. An electron microscopic study of dystrophic axons in the gracile and cuneate nuclei of vitamin E-deficient rats. J. Neuropath. exp. Neurol. 1964, 23, 60.

58. Parnell-King, J. Neuronal changes in spinal cord of mice on vitamin $\mathrm{E}$ and fat deficient diets (abstract). Anat. Rec. 1964, 148, 320.

59. Sobrevilla, L. A., M. L. Goodman, and C. A. Kane. Demyelinating central nervous system disease, macular atrophy and acanthocytosis (Bassen-Kornzweig syndrome). Amer. J. Med. 1964, 37, 821. 